\title{
Working together to share the dental neglect
}

\author{
R. Jameson*1
}

\section{In brief}

Highlights the important role dentists have in safeguarding children.
Describes diagnosing dental neglect in children, and the role of communication with other professionals.
Considers the benefits of appropriate dental information sharing, including provision of care for a child's global wellbeing and for safeguarding purposes.
Suggests an effective solution to the barriers of appropriate information sharing.

This safeguarding in dentistry article encourages wider healthcare information sharing in dental neglect in children. It describes the development of a local procedure for healthcare information sharing following dental extraction in children under general anaesthetic. This appropriate information sharing may be used to inform healthcare practitioners' assessments of the health needs of the child, family support and education, or for safeguarding purposes.

\section{Background}

In services that care for children, we are aware that working together is a key principle in safeguarding children and protecting them from harm. Working together to Safeguard Children, published in 2015 by HM government, ${ }^{1}$ identifies that: 'Early sharing of information is the key to providing effective early help where there are emerging problems. At the other end of the continuum, sharing information can be essential to put in place effective child protection services.'

Within the dental profession there is a growing understanding in the role the dental team has in identifying and reporting vulnerable children at risk of significant harm. Ten years ago the safeguarding guidance and website in dentistry 'Child protection and the dental team', $\mathrm{CPDT}^{2}$ was launched.

In my role as a named doctor for safeguarding children for a community health provider, it became apparent that outside dentistry, healthcare practitioners and other agencies such as children's social care were often unaware of a child's dental disease and how it impacted on the child's wellbeing and health. A local example was that when a child underwent dental extraction for dental caries under general anaesthetic, the discharge letter was sent to the GDP. This

${ }^{1}$ Named Doctor for Safeguarding Children, Livewell Southwest

${ }^{*}$ Correspondence to: Rachel Jameson

Email: racheljameson@nhs.net

Refereed Paper. Accepted 23 November 2016

DOI: $10.1038 /$ sj.bdj.2016.943

${ }^{\oplus B}$ British Dental Journal 2016; 221: 755-756 information was not shared with the community health team such as the GP, the school nurse or health visitor.

Dental extraction rates in the UK are high, with dental caries being the most common reason for children aged between five and nine to be admitted to hospital. ${ }^{3}$ Of these children, some will suffer from dental neglect, defined as 'the persistent failure to meet a child's basic oral health needs, likely to result in the serious impairment of a child's oral or general health or development."

There are a number of factors a dentist must consider before diagnosing dental neglect. Sometimes these are not apparent to the dentist, and communicating with other professionals who know the child is appropriate. In addition, it is suspected that there may often be coexisting signs of general neglect ${ }^{5}$ which may require communication with other healthcare professionals to assess. The same article reported the findings that only a small proportion of paediatric dentists were regularly communicating with other health and social care professionals.

It would appear we are missing opportunities to safeguard vulnerable children as we are failing to communicate and share appropriate health information in dental neglect.

\section{Improving information sharing}

The area of dental information sharing that had been identified for improvement locally was healthcare information sharing following dental extraction in children under general anaesthetic. The goal of the dental information sharing was to inform healthcare practitioners' assessments of the health needs of the child, family support and education, or for safeguarding purposes.

To improve this process in my local area I co-facilitated a meeting with the key stakeholders in health. These included the safeguarding lead for the acute hospital trust where the extractions took place, the dental team, the children's day theatre leads and my role as the community team safeguarding lead.

With no extra resource available for the introduction of the procedure, we worked the procedure within the current resources, which included three different IT systems for patient records, clinical (dental, day theatre staff and community health) time, and administrative time. We had the current figures of numbers of children who underwent dental extraction per month, which were up to 80 . We identified the children at greatest risk of dental neglect to prioritise sharing their dental information. This clinical expertise was provided by the dental clinical lead, and with input from the named child protection professionals. The other issues included how the information was to be included in the child's acute trust's hospital notes, and shared with the community team. We found pragmatic solutions, adapting existing systems, for these issues. The procedure also addressed that the parent or carer would have to consent to information sharing outside the unit with other healthcare professionals.

With universal agreement, a procedure was written and integrated into the current operational policy and procedures for the dental services and for the children's day case theatre. 


\section{Wider learning and application}

Please do not overlook the importance of dental healthcare information in a child's wellbeing. I implore you to approach your healthcare colleagues, and use the expertise of your local safeguarding leads (from the CCG, community or acute hospital trust as appropriate) to facilitate discussion and policy development to improve the communication of appropriate dental service information to other healthcare providers. This appropriate information sharing is valuable in providing care and support for a child's wellbeing, as well as for safeguarding purposes.

1. HM Government. Working Together to Safeguard Children. 2015. Available online at http://www. workingtogetheronline.co.uk/chapters/chapter_one. html\#information (accessed July 2016).

2. Harris J, Sidebotham P, Welbury R et al. Child protection and the dental team: an introduction to safeguarding children in dental practice. Sheffield: Committee of Postgraduate Dental Deans and Directors (COPDEND)
UK, 2006. Information available online at www.cpdt. org.uk (accessed November 2016).

3. The Faculty of Dental Surgery. The state of children's oral health in England. 2015. Information available online at https://www.rcseng.ac.uk/library-and-publications/ college-publications/docs/report-childrens-oral-health/ (accessed November 2016).

4. Harris J, Balmer R C, Sidebotham P D. British Society of Paediatric Dentistry: a policy document on dental neglect in children. Int J Paediatric Dent 2009; DOI: 10.1111/j.1365-263X.2009.00996.x.

5. Harris J C, Elcock C, Sidebotham P D, Welbury R R. Safeguarding children in dentistry: 2. Do paediatric dentists neglect child dental neglect? Br Dent J 2009; 206: $465-470$. 